\title{
Anatomic Relationships of Mandibular Canal. A Cone Beam CT Study
}

\author{
Relaciones Anatómicas del Canal Mandibular. \\ Un Estudio en Tomografías Computarizadas de Haz de Cono
}

Gonzalo Muñoz'; Fernando José Dias²; Benjamin Weber²; Pablo Betancourt² \& Eduardo Borie ${ }^{2}$

MUÑOZ, G.; DIAS, F. J.; WEBER, B.; BETANCOURT, P. \& BORIE, E. Anatomic relationships of mandibular canal. A cone beam CT study. Int. J. Morphol., 35(4):1243-1248, 2017.

SUMMARY: It is critical to know the precise location and configuration of the mandibular canal (MC) to avoid damages in the alveolar inferior nerve during an invasive dental treatment. The aim of this study was to provide anatomic relationships of the mandibular canal in its entire pathway related to cortical walls and dental roots to serve as basic knowledge for dental clinical procedures performed in this area. We analyzed $50 \mathrm{CBCT}$ images assessing the specific location of $\mathrm{MC}$ at the retromolar space as related to inferior teeth roots. Data were analyzed by side using descriptive statistics (median: mean [M], standard deviation [SD], $95 \%$ confidence interval: lower endpoint [IC] and upper endpoint [IC']). The MC length and pathway were measured from the mandibular foramen up to the mental foramen. MC was closer from lingual cortical than buccal at the retromolar space as well the distal root of the second molar and the root of the second premolar are closest to MC. A mean length for the MC of $70.8( \pm 5.3 \mathrm{~mm})$ for the right side and 71 ( $\pm 5.8 \mathrm{~mm})$ for the left side were observed. In conclusion, it is critical for clinicians to know three-dimensionally the topographic relationships between the inferior teeth roots and the mandibular canal before proceeding to any invasive dental or surgical procedure at this region.

KEY WORDS: Mandibular canal; Cone beam computed tomography; CBCT scans; Dental treatment.

\section{INTRODUCTION}

Mandibular canal (MC) is a bony structure that begins in the mandibular foramen on the medial face of mandible ramus. Its pathway follows the lower and lateral direction passing to the mandible body, where it is related to the roots of the lower teeth, whose cross-sectional examination reveals an oval, circular or piriform shape (Suazo et al., 2011).

The mandibular canal carries, from its origin until the incisive region, the inferior alveolar artery and vessel and inferior alveolar nerve. The branches derived from these structures provide nerve and vascular supply to the lower teeth and adjacent structures; a terminal branch leaves the canal through the mental foramen emerging as the mental nerve (Claeys \& Wackens, 2005). The inferior alveolar nerve is a major division of the trigeminal nerve, which is vulnerable in surgical procedures of the mandible (Kilic et al., 2010). The physiology of the mandibular nerve is an important factor relevant to success in dental implant planning and surgical procedures in the mandible (Karnasuta et al., 2017).
The morphological features of the mandibular canal, its variations and inner vital structures are very significant especially in oral anesthesia, dental implant therapy and maxillofacial surgery, because the inferior alveolar neurovascular bundle presents different locations and many variations (Juodzbalys et al., 2010; Roa \& Arriagada, 2015). MC may be damaged by mechanical trauma through irrigants during an endodontic treatment, drilling, root canal over instrumentation, third molar exodontia or damage during implant location (Kawashima et al., 2016; Koivisto et al., 2016). The last procedure has gained popularity in the last few years, as it requires to optimize and plan the surgery considering the distance from the $\mathrm{MC}$ due to the considerable paresthesia and nerve damage observed in the literature, to which prevalence ranges are between 13-17\% (Kubilius et al., 2004; Burstein et al., 2008).

In this sense, it is imperative to know the precise location and configuration of MC to avoid damages in the alveolar inferior nerve (Juodzbalys et al.; Hsu et al., 2013;

\footnotetext{
${ }^{1}$ Master student in Orthotontics, Federal University of Rio de Janeiro (UFRJ), Rio de Janeiro, Brazil.

${ }^{2}$ CICO Research Centre, Universidad de La Frontera, Temuco, Chile.
} 
Kawashima et al.). Thus, the aim of this study is to provide anatomic relationships of the mandibular canal in its entire pathway related to cortical walls and dental roots to serve as a basic knowledge for dental clinical procedures performed in this region.

\section{MATERIAL AND METHOD}

This study was approved by the Scientific Ethics Committee of the Universidad de La Frontera, Temuco, Chile (Protocol $\mathrm{N}^{\circ}$ 048/13). A descriptive study was performed on $50 \mathrm{CBCT}$ images, which belong to the radiology unit of the Universidad de La Frontera, taken between January 2014 and March 2015. The patients identities were not revealed and only access to information regarding age and gender was provided. The images were taken as part of the diagnosis, examination and treatment planning of surgical, endodontic, periodontal, orthodontic or rehabilitation treatments. The images were obtained on a Pax Zenith CBCT unit (Vatech, Hwaseong-si, Korea), using $120 \mathrm{kV}$ and $9 \mathrm{~mA}$; FOV $8 \times 6 \mathrm{~cm}$, voxel size $0.12 \mathrm{~mm}$.

Data were exported as DICOM format in the software EZ3D2009 (E-WOO Technology Co. Ltd. Korea) to observe coronal, sagittal and axial cuts as well as a 3D reconstruction. Inclusion criteria were aged between 15 and 75 years, and mandibular fully dentate individuals. Exclusion criteria were images with implants in mandible, bone resorption related to periodontal disease or endodontics and endodontic treatment.

Two calibrated examiners performed the morphometric analyses. Coronal and sagittal cuts were oriented parallel to the long axis of the mandible, and then cuts were obtained at $0.5 \mathrm{~mm}$ intervals and $1 \mathrm{~mm}$ in thickness for all the samples, using multiplanar reformatting (MPR). MPR allows making a three-dimensional model showing all structures within $1 \mathrm{~mm}$ thickness overlapped on each other.

The exact location of mandibular canal was assessed at different depths on the sagittal cuts. The complete plotting of mandibular canal was made using the sagittal image, beginning from the distal side in direction to mesial side. Also, the distance between mandibular canal and dental apex from teeth 4.7-4.6-4.5 was measured throughout the coronal cuts. Then, a parallel line to the dental contact point of premolars was designed and then the distance between the mental foramen and this parallel line was measured. When the mental foramen was at left side of this line, a negative value was assigned to this measure and when was at the right side it had a positive value.

A coronal cut at the retromolar space was made, and three lines, A, B and C, were measured. Line A was measured between mandibular canal and mandible's buccal cortical bone. Line B was determined between mandibular canal and mandible's lingual cortical bone; and Line $\mathrm{C}$ was performed between mandibular canal and the base of mandible.

Data were analyzed by side using descriptive statistics (median: mean [M], standard deviation [SD], $95 \%$ confidence interval: lower endpoint [IC] and upper endpoint [IC']).

Finally, the mandibular canal length and pathway were measured from the mandibular foramen up to the mental foramen.

\section{RESULTS}

The distance between mandibular canal and the cortical limits of the mandible is summarized in Table I. Mandibular canal was closer from lingual cortical than buccal at the retromolar space as observed in Figure 1. Also, the distance between dental roots of each tooth and mandibular canal is observed in Table II and Figure 2. As can be seen, the distal root of the second molar and the root of the second premolar are closest to mandibular canal.

Finally, a mean length for the mandibular canal of 70.8 $( \pm 5.3 \mathrm{~mm})$ for the right side and $71( \pm 5.8 \mathrm{~mm})$ for the left side were observed. Also, $95 \%$ confidence intervals for right and left sides were 69.1-72.5 mm and 69.2-72.9 mm, respectively.

Table I. Distance between mandibular canal and cortical limits of mandible at retromolar space.

\begin{tabular}{lcccc}
\hline Distance of MC from & Side & Mean $(\mathbf{m m})$ & S.D. & Median \\
\hline Basilar edge & Right & 8.5 & 2.6 & 7.9 \\
& Left & 7.7 & 2.7 & 7.8 \\
Buccal cortical & Right & 4.3 & 1.7 & 4.1 \\
& Left & 4.8 & 1.8 & 4.8 \\
Lingual cortical & Right & 2.3 & 1.3 & 1.9 \\
& Left & 2.2 & 1.4 & 1.9 \\
\hline
\end{tabular}


MUÑOZ, G.; DIAS, F. J.; WEBER, B.; BETANCOURT, P. \& BORIE, E. Anatomic relationships of mandibular canal. A cone beam CT study. Int. J. Morphol., 35(4):1243-1248, 2017.

Table II. Distance between dental roots of each tooth and mandibular canal.

\begin{tabular}{lcccc}
\hline Measureme nts & Side & $\begin{array}{c}\text { Mean } \\
(\mathbf{m m})\end{array}$ & S.D. & Median \\
\hline Second molar, distal root & Right & 4.7 & 2.6 & 4.3 \\
& Left & 3.9 & 2.4 & 3.6 \\
Second molar, mesial root & Right & 5.4 & 2.7 & 5.1 \\
& Left & 4.8 & 2.9 & 4.6 \\
First molar, distal root & Right & 5.6 & 2.1 & 4.9 \\
& Left & 5.4 & 2.5 & 4.8 \\
First molar, mesial root & Right & 6.0 & 2.5 & 5.4 \\
Second premolar & Left & 5.6 & 2.4 & 4.7 \\
& Right & 4.1 & 3.7 & 2.7 \\
Distance between mental foramen & Left & 3.9 & 3.2 & 2.7 \\
to premolars contact point & Right & 0.3 & 2.3 & 0 \\
& Left & -0.5 & 1.7 & 0 \\
\hline
\end{tabular}

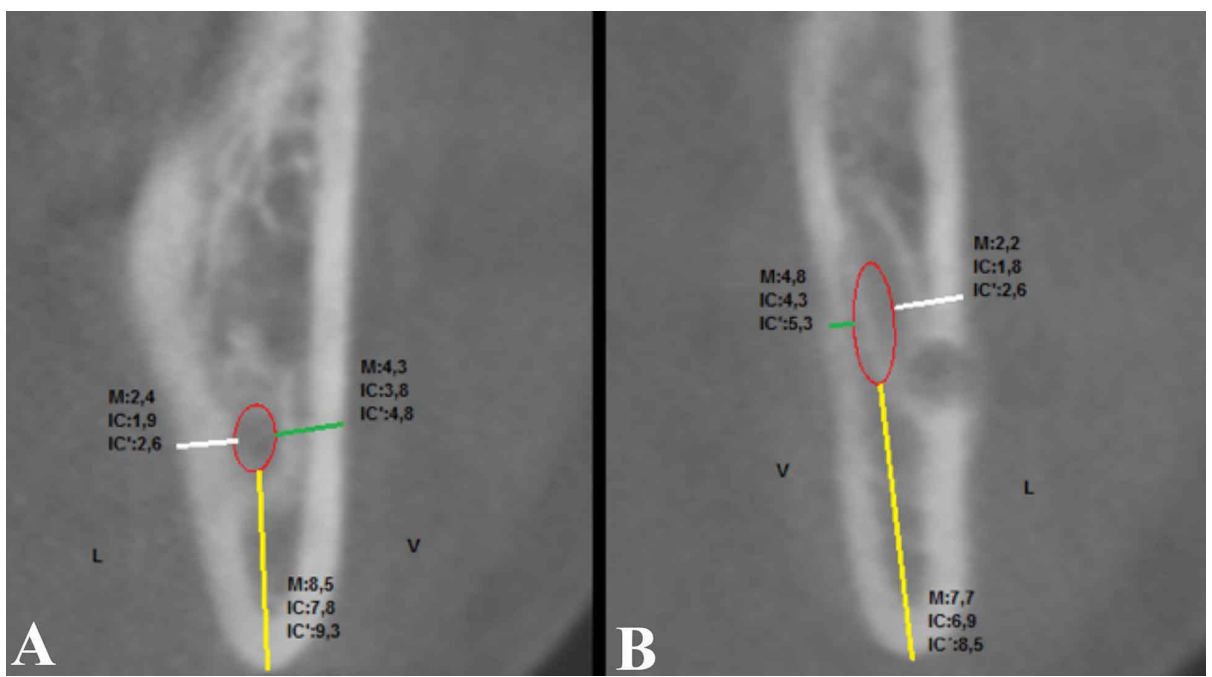

Fig.1. Distance between mandibular canal and buccal cortical (V), lingual cortical (L) and base of mandible $(\mathrm{BM})$ in retromolar space at right $(\mathrm{A})$ and left side $(\mathrm{B})$.

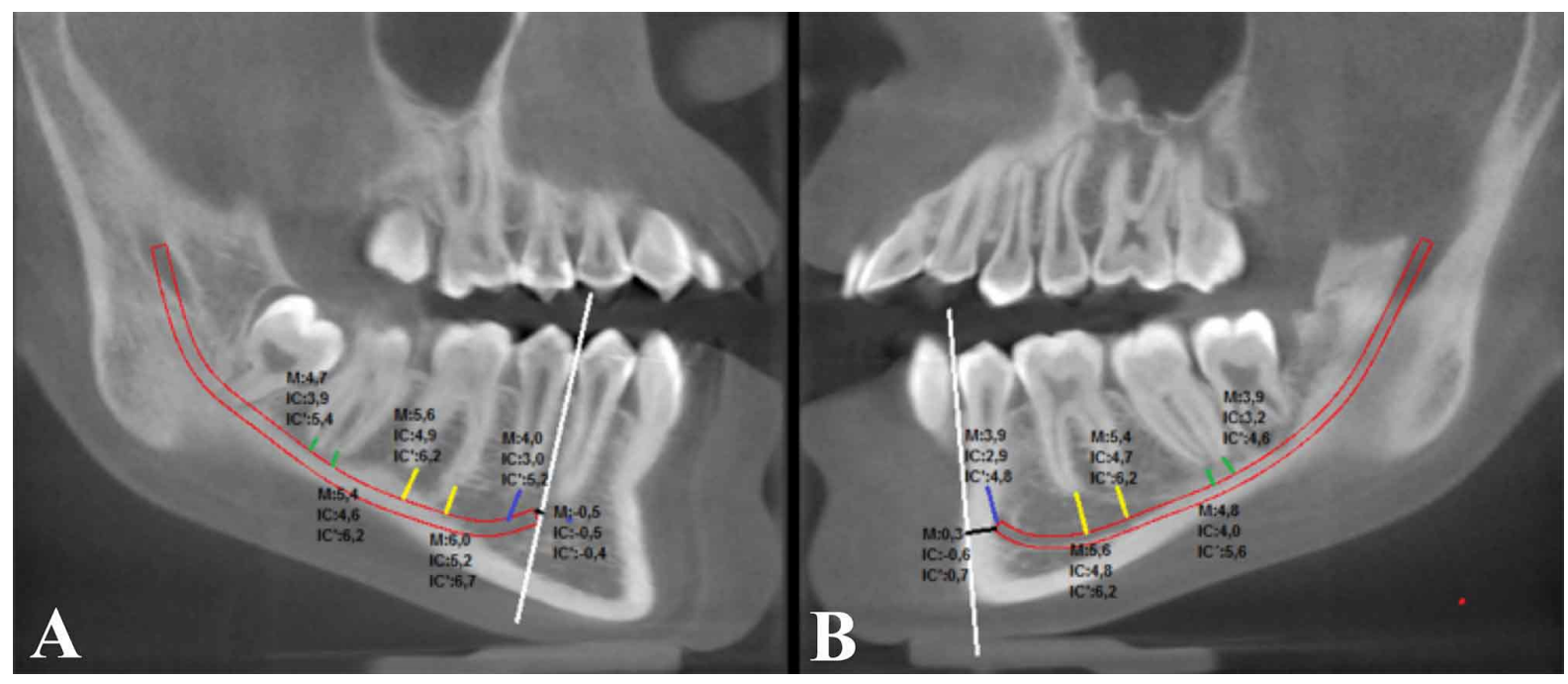

Fig. 2. Mean distance between dental roots of each tooth and mandibular canal at right (A) and left side (B). 


\section{DISCUSSION}

The present study evaluated the morphological and morphometric characteristics of the mandibular canal (MC) of Chilean fully dentate patients using CBTC images, focusing mainly on the measurements of distance from this canal to the mandibular cortical walls and base and its relation to posterior teeth roots. These data may serve as a basic knowledge for clinicians during a surgical or endodontic treatment performed in mandible's posterior region to reduce the damage to alveolar inferior nerve.

The location of the MC by the frontal view of the crosssection of the jaw body showed that MC is located closer to the lingual cortical at retromolar space. Kumar Potu et al. (2013) described the MC pathway in a cross-section view of mandible, reporting that MC crosses lingually to the third and second molars roots, adjacent to first molar roots and buccally from the premolars. At the retromolar space, the distance from the $\mathrm{MC}$ to the buccal cortical presented values close to twice of those observed to the lingual cortical, while the distance to the mandibular base was approximately fourfold to the lingual cortical. A tendency was also observed that MC was located more lingual at right side, which concurs with de Oliveira Júnior et al. (2011), but without significant differences. The MC is often symmetrical bilaterally (Nortjé et al., 1977).

Previous studies (Levine et al., 2007; Kamburoglu et al. 2009; Koivisto et al., 2016; Uppal et al. 2017) revealed distances of the MC to both corticals, ranging from 1.7-4.35 $\mathrm{mm}$ and 2.6-5.4 mm for lingual and buccal walls, respectively. These measurements are higher than those observed in our population but according to the reports by Huang \& Liao (2015) who identified mean values of the MC distance to lingual cortical less than $2.7 \mathrm{~mm}$. Jasa et al. (2014) revealed that there was a higher prevalence of MC near buccal mandibular cortical $(65.7 \%)$ when compared to basilar edge $(25.7 \%)$ and lingual $(8.6 \%)$. These differences may be due to different evaluation technique, since Jasa et al. used lateral oblique radiographs in anatomical specimens. Huang \& Liao stated that $\mathrm{MC}$ is closer to lingual wall at the two posterior thirds of mandible, which concurs with the observation in this research.

Other studies corroborate the observation of the present study whose position of MC in relation to the cortical bone of the basilar edge is considerably higher in relation to the lingual and buccal walls (Uppal et al.; Killic et al.), with mean values of 7 to $7.94 \mathrm{~mm}$ (Yu \& Wong, 2008; Uppal et al.) and 10.52 mm (Gowgiel, 1992; Killic et al.; Juodzbalys et al.). The mean values observed in the present study are closer to those reported by Yu \& Wong and Uppal et al.
In addition to the distance of the MC to cortical walls, its relationship to the dental roots is of great academic and practical importance due to surgical and endodontic procedures in the mandible, which presents the possibility of complications to the mandibular canal and its components (Littner et al., 1986).

The distance from the mandibular canal to the dental apices assessed by lateral view (sagittal sections) revealed values of each dental root of the posterior region based on its trajectory, which begins in the mandibular foramen located in the ramus, followed by a descending and anterior trajectory to the region of premolars. From that point, the MC shows an ascending and anterior pathway until the region of mental foramen. The pathway of the MC was reflected in the present study in closer distances from MC to dental apices from second molars, concurring with some studies (Koivisto et al., 2011; Bürklein et al., 2015), and observing increasing values until the ascending pathway at the second premolars region, at the emergence of mental foramen.

The literature (Littner et al.; Koivisto et al. 2011; Bürklein et al.), shows similar characteristics to those observed in the present study regarding distance from MC to posterior tooth apices. In general, an increase in this distance exists in the evaluation of distal apices from the second molar to the mesial root of the first molar, with subsequent reduction of this distance in relation to the second premolars. It is important to point out that in most cases at the left side, the emergence of MC in the mental foramen was located between the first molar and second premolar.

Related to the distance between the MC from second molar roots, the findings of this study were a little higher than the reports of Bürklein et al. $(2.8 \mathrm{~mm})$, but considerably different when compared with the study of Sato et al. (2005) performed in panoramic radiographs $(0.7 \mathrm{~mm})$. The distance from the first molar roots was similar to that reported in some studies (Bornstein et al., 2011; Bürklein et al.); however, it was significantly different from the findings of Koivisto et al. (2011) (2.3mm) and Sato et al. (1 mm). Also, the distance from second premolar to $\mathrm{MC}$ reported by Koivisto et al. (2016) (2.6mm) was lower than that of the values identified in this study (4.1-3.9 mm).

The differences observed with previous researches may be explained by the population studied and the technique of analysis used for the location of MC, observing studies that were performed directly in anatomical pieces (Killic et al.; Kamburoglu et al.), in panoramic radiographs (Littner 
et al.; Sato et al.; Jasa et al.) and CBCT scans (Kamburog `lu et al.; Uppal et al.; Koivisto et al., 2016). In this sense, the CBCT is the 'gold standard' method in which three dimensional images are obtained with high precision of measurements, which allow to analyze clinically structures close to the $\mathrm{MC}$, with a high resolution, low dose radiation and minimal distortion when compared to panoramic radiographs (Jasa et al.; Hsu et al.; Koivisto et al. 2016; He et al., 2016).

In conclusion, it is critical to clinician to know threedimensionally the topographic relationships between the inferior teeth roots and the mandibular canal before proceeding to any invasive dental or surgical procedure at this region.

\section{ACKNOWLEDGEMENTS}

The authors want to acknowledge to the insertion program, DI16-6010 project.

MUÑOZ, G.; DIAS, F.J.; WEBER, B.; BETANCOURT, P.; BORIE, E. Relaciones anatómicas del canal mandibular. Un estudio en tomografías computarizadas de haz de cono. Int. J. Morphol., 35(4):1243-1248, 2017.

RESUMEN: Es crítico conocer la ubicación exacta y la configuración del canal mandibular (MC) para evitar daños en el nervio inferior alveolar durante un tratamiento dental invasivo. El objetivo de este estudio fue proporcionar relaciones anatómicas del MC en toda su trayectoria relacionada con paredes corticales y raíces dentales para servir como un conocimiento básico para los procedimientos clínicos dentales realizados en esta región. Se analizaron 50 imágenes $\mathrm{CBCT}$ evaluando la localización específica del MC en el espacio retromolar, así como las raíces de los dientes inferiores. Los datos se analizaron por lado, utilizando estadística descriptiva (mediana: media [M], desviación estándar [SD], $95 \%$ intervalo de confianza: punto final inferior [IC] y extremo superior [IC]). La longitud y vía del conducto mandibular se midieron desde el foramen mandibular hasta el foramen mentoniano. El MC estaba más cerca de la cortical lingual que bucal en el espacio retromolar, así como la raíz distal del segundo molar y la raíz del segundo premolar están más cerca del MC. Se observó una longitud media para el MC de 70,8 ( $\pm 5,3 \mathrm{~mm})$ para el lado derecho y de $71( \pm 5,8 \mathrm{~mm})$ para el lado izquierdo. En conclusión, es fundamental que el clínico conozca tridimensionalmente las relaciones topográficas entre las raíces de los dientes inferiores y el conducto mandibular antes de proceder a cualquier procedimiento invasivo dental o quirúrgico en esta región.

PALABRAS CLAVE: Canal mandibular; Tomografía computarizada de haz de cono; CBCT escáner; Tratamiento dental.

\section{REFERENCES}

Bornstein, M. M.; Lauber, R.; Sendi, P. \& von Arx, T. Comparison of periapical radiography and limited cone-beam computed tomography in mandibular molars for analysis of anatomical landmarks before apical surgery. $J$. Endod., 37(2):151-7, 2011.

Bürklein, S.; Grund, C. \& Schäfer, E. Relationship between root apices and the mandibular canal: A cone-beam computed tomographic analysis in a German population. J. Endod., 41(10):1696-700, 2015.

Burstein, J.; Mastin, C. \& Le, B. Avoiding injury to the inferior alveolar nerve by routine use of intraoperative radiographs during implant placement. J. Oral Implantol., 34(1):34-8, 2008.

Claeys, V. \& Wackens, G. Bifid mandibular canal: literature review and case report. Dentomaxillofac. Radiol., 34(1):55-8, 2005.

de Oliveira Júnior, M. R.; Saud, A. L.; Fonseca, D. R.; De-Ary-Pires, B.; Pires-Neto, M. A. \& de Ary-Pires, R. Morphometrical analysis of the human mandibular canal: a CT investigation. Surg. Radiol. Anat., 33(4):345-52, 2011

Gowgiel, J. M. The position and course of the mandibular canal. J. Oral. Implantol., 18(4):383-5, 1992.

He, X.; Jiang, J.; Cai, W.; Pan, Y.; Yang, Y.; Zhu, K. \& Zheng, Y. Assessment of the appearance, location and morphology of mandibular lingual foramina using cone beam computed tomography. Int. Dent. J., 66(5):2729, 2016.

Hsu, J. T.; Huang, H. L.; Fuh, L. J.; Li, R. W.; Wu, J.; Tsai, M. T.; Shen, Y. W. $\&$ Tu, M. G. Location of the mandibular canal and thickness of the occlusal cortical bone at dental implant sites in the lower second premolar and first molar. Comput. Math. Methods Med., 2013:608570, 2013.

Huang, C. Y. \& Liao, Y. F. Anatomical position of the mandibular canal in relation to the buccal cortical bone in Chinese patients with different dentofacial relationships. J. Formos. Med. Assoc., 115(11):981-90, 2016.

Jasa, G. R.; Vizzoto, M. B.; da Silveira, P. F.; da Silveira, H. E. D.; da Silveira, H. L. D.; Correa, L. R. \& Raveca, T. Buccal-lingual localization of the mandibular canal in relationship with the third molar using the lateral oblique technique. J. Oral Maxillofac. Radiol., 2(1):15-20, 2014.

Juodzbalys, G.; Wang, H. L. \& Sabalys, G. Anatomy of mandibular vital structures. Part I: mandibular canal and inferior alveolar neurovascular bundle in relation with dental implantology. J. Oral Maxillofac. Res., 1(1):e2, 2010

Kamburoglu, K.; Kiliç, C.; Ozen, T. \& Yüksel, S. P. Measurements of mandibular canal region obtained by cone-beam computed tomography: a cadaveric study. Oral Surg. Oral Med. Oral Pathol. Oral Radiol. Endod., 107(2):e34-42, 2009.

Karnasuta, P.; Plianrungsi, J.; Denkongpon, I.; Horsimasathaporn, N.; Chayutthanabun, P.; Weerachartwattana, J.; Boonchalermchai, P.; Charoenwathana, S.; Narongrat, N.; Jutipimarn, K.; Hongsatit, N. \& Tharanon, W. Cone-beam computed tomography investigation of crucial mandibular canal variations in Thais. Oral Radiol., 2017. DOI: 10.1007/ s11282-017-0270-3.

Kawashima, Y.; Sakai, O.; Shosho, D.; Kaneda, T. \& Gohel, A. Proximity of the mandibular canal to teeth and cortical bone. J Endod., 42(2):221-4, 2016.

Kilic, C.; Kamburoglu, K.; Ozen, T.; Balcioglu, H. A.; Kurt, B.; Kutoglu, T. \& Ozan, $\mathrm{H}$. The position of the mandibular canal and histologic feature of the inferior alveolar nerve. Clin. Anat., 23(1):34-42, 2010.

Koivisto, T.; Chiona, D.; Milroy, L. L.; McClanahan, S. B.; Ahmad, M. \& Bowles, W. R. Mandibular canal location: Cone-beam computed tomography examination. J. Endod., 42(7):1018-21, 2016.

Kovisto, T.; Ahmad, M. \& Bowles, W. R. Proximity of the mandibular canal to the tooth apex. J. Endod., 37(3):311-5, 2011.

Kubilius, R.; Sabalys, G.; Juodzbalys, G. \& Gedrimas, V. Traumatic damage to the inferior alveolar nerve sustained in course of dental implantation. Possibility of prevention. Stomatologija Baltic Dent. Maxillofac. J., 6(4):106-10, 2004. 
Kumar Potu, B.; Jagadeesan, S.; Bhat, K. M. \& Rao Sirasanagandla, S. Retromolar foramen and canal: a comprehensive review on its anatomy and clinical applications. Morphologie, 97(317):31-7, 2013.

Levine, M. H.; Goddard, A. L. \& Dodson, T. B. Inferior alveolar nerve canal position: a clinical and radiographic study. J. Oral Maxillofac. Surg., 65(3):470-4, 2007.

Littner, M. M.; Kaffe, I.; Tamse, A. \& Dicapua, P. Relationship between the apices of the lower molars and mandibular canal--a radiographic study. Oral Surg. Oral Med. Oral Pathol., 62(5):595-602, 1986.

Nortjé, C. J.; Farman, A. G. \& Grotepass, F. W. Variations in the normal anatomy of the inferior dental (mandibular) canal: a retrospective study of panoramic radiographs from 3612 routine dental patients. Br. J. Oral Surg., 15(1):55-63, 1977.

Roa, I. \& Arriagada, O. Anatomical variations of mandibular canal with clinical significance. Case report. Int. J. Morphol. 33(3):971-4, 2015.

Sato, I.; Ueno, R.; Kawai, T. \& Yosue, T. Rare courses of the mandibular canal in the molar regions of the human mandible: a cadaveric study. Okajimas Folia Anat. Jpn., 82(3):95-101, 2005.

Suazo, G. I.; Matamala, Z. D. \& Cantín, L. M. Accessory mandibular canal: analysis of prevalence and imaging appearance. $A v$. Odontoestomatol., 27(2):85-90, 2011.

Uppal, M. K.; Asha, I. R.; Seema, P.; Ramya, M. K.; Subash, B. V. \& Kumar, J. R. Radiomorphometric localization of mental foramen and mandibular canal using cone beam computed tomography as an aid to gender determination-A retrospective study. Tricity J. Healthc. Res., 1(2):216, 2017.

Yu, I. H. \& Wong, Y. K. Evaluation of mandibular anatomy related to sagittal split ramus osteotomy using 3-dimensional computed tomography scan images. Int. J. Oral Maxillofac. Surg., 37(6):521-8, 2008.
Corresponding author:

Eduardo Borie E.

Departmento Odontología Integral del Adulto

Facultad de Odontología

Universidad de la Frontera

Av. Francisco Salazar 01145

Temuco

Chile

E-mail: eduardo.borie@ufrontera.cl

Received: 23-07-2017

Accepted: 21-09-2017 